\title{
STANDARDIZATION OF SALARIES IN AMERICAN CITIES
}

\author{
BY WILLIAM C. BEYER ${ }^{1}$ \\ Philadelphia
}

$\mathbf{S}^{\mathrm{T}}$

TANDARDIZATION of salaries forms an essential part of two distinct programs for improving the effectiveness of public administration. One is that of civil service reform which aims primarily to increase the efficiency of the personnel charged with carrying out the administrative functions of government. Civil service commissions throughout the country have come to realize that the merit principle cannot be applied fairly and effectively to promotions within the public service unless something is done to correct the confusion and chaos on the average city payroll.

The other program is that of the efficiency movement which concentrates attention mainly on procedure and method. The processes of internal administration are examined and readjusted to effect greater efficiency and economy in the operation of government. Budget making, accounting methods, purchasing procedure and similar matters of administration have been made subjects of inquiry and constructive study by efficiency bodies in many of our larger cities. Since the amount of money spent for personal service usually constitutes the biggest single item in a city's annual outlays, it is only natural that the payroll should be subjected to similar scrutiny and revision.

It will be of interest to inquire briefly what this scrutiny has revealed and what is being done to correct the evils discovered.

One of the shortcomings found in most American cities is that salaries are fixed without sufficient knowledge of the duties of positions. As a rule the legislative body is required to pass upon requests for changes in the payroll without any basis of information for determining the reasonableness of such requests except the representations of department heads and the titles of the positions under consideration. The limitations of following implicitly the recommendations of department heads are obvious at once. Too much is made to depend upon these officials who may be acting under strong personal or political pressure. Titles, in their turn, are often misleading and cannot be relied upon to indicate the character and importance of the posts to which they are attached. To illustrate: Anyone, upon glancing down the payroll of a certain Eastern city and coming to the title "superintendent of I__- Park," would naturally suppose that this official had custody of a park at some distance from the center of the city and was charged with considerable responsibility;

${ }^{1}$ Of the Philadelphia Bureau of Municipal Research. 
further inquiry would disclose the fact that he was employed as a clerk in one of the offices at the city hall and had nothing whatever to do with the management of any park. The average legislator, however, has not the time to make a personal investigation of each case of this character that comes before him during the busy budget making season when salary ordinances are usually considered. The result is that in the majority of instances he is compelled to act without adequate information about the positions in which changes are contemplated.

\section{CONSIDERING SERVICE IN ITS ENTIRETY}

Another imperfection in the usual method of fixing salaries is the absence of opportunity to consider the service in its entirety and to secure uniformity in the standards of compensation in the different branches of government. As a rule the salary needs of each department are considered by themselves and with slight regard to those of other departments. Little effort is made to consider positions in groups and to confine rates of pay for similar employments within definite ranges. Too often the fact that Jones happens to occupy a certain position has greater weight in determining the amount of salary than the character and grade of duties which the position involves. In consequence of these conditions we find on municipal payrolls the most glaring discrepancies and irregularities in the salary rates for the same kinds of service.

A third criticism that should be mentioned is the fact that, for the most part, no distinction in salary is made between an employe who has had long experience in a certain position and a new appointe who is wholly unfamiliar with the work. Obviously a clerk who is worth $\$ 900$ at the start ought to be worth considerably more at the end of several years of satisfactory service, and to leave his salary unchanged is doing him an injustice which may dampen his enthusiasm and ultimately reduce his efficiency. If, on the other hand, he begins at $\$ 900$ and is worth no more after having held the position for two or three years, then it is fair to assume that he was overpaid in the beginning. In either case the employe is robbed of incentive by having to continue at the same rate of pay year after year and the entire force suffers from the demoralizing effect of such an unfair method of compensation. The corollary of this practice is to increase salaries in isolated instances to reward long and faithful service, and then to leave them unchanged for inexperienced successors when vacancies occur. The taxpayer, of course, must foot the bill.

Bearing in mind the unscientific and haphazard methods by which salaries are usually fixed, what can be said for a scheme of promotion which is based on a grading of positions according to rates of compensation? Manifestly, it could not be more scientific nor more equitable than the salary rates themselves. Yet, until very recently, all civil service classifications in this country were based on compensation, and 
the majority of them are on that basis still. Since salaries and duties in most cities are not necessarily co-ordinate, it is possible under such a classification that promotion in grade and salary might mean actual demotion in character of work, and vice versa. Moreover, the misleading titles are as harassing to civil service commissions in their endeavor to fit the man to the job as they are to appropriating bodies when salary changes are being considered. It goes without saying that in those branches of public service in which the primeval chaos still remains undisturbed, it is difficult for employes, or even civil service administrators, to discover many real lines of promotion. Blind alleys far outnumber the open avenues to higher employments. The result is that employes become discouraged and lose all interest and zeal in their work.

\section{CHICAGO'S EXPERIMENTS}

The first notable effort to correct these conditions was made recently in Chicago. In 1908 the civil service commission of that city enlisted the co-operation of the city council in a standardization program which embraced, among other things, the reclassification of the service according to duties and the adoption of uniform salary rates for similar positions. Early in the following year, Mayor Busse appointed the municipal efficiency commission which acted for a time as the co-ordinating force between the civil service body and the city council in working out the details of the program. Later this commission was superseded by the efficiency division of the civil service commission itself. By the end of 1910 the reclassification of positions was practically completed and a beginning had been made on the adjustment of salaries to the new grades, which was continued during 1911 . On July 15, 1912, the city council passed an ordinance which gave official recognition to the standardization scheme adopted by the civil service commission. 'Since that time the annual appropriations for salaries have been made in accordance with the provisions of this scheme.

The outstanding features of the Chicago standardization may be stated briefly as follows: First, all positions under civil service rules are classified, according to the general character of the duties involved, into eleven distinct classes, known as the medical, engineering, clerical, police, operating engineering, fire, library, inspection, supervising, skilled labor, and labor services. Second, the positions in each distinct class, or service, are divided into grades according to their relative authority, importance and responsibility. Third, for each grade a salary schedule is established providing minimum, maximum and intermediate rates that apply uniformly to all positions within the grade. Fourth, promotion from a lower to a higher grade is made subject to a competitive promotion examination, but advancement from a lower salary rate to the next higher rate within a grade is made to depend on efficiency and length of service. 
Fifth, efficiency of employes is ascertained from efficiency markings reported regularly by department heads in accordance with instructions submitted to them by the civil service commission. Sixth, titles of positions are standardized and made descriptive of actual duties. ${ }^{2}$

Since Chicago did its pioneer work in salary standardization a number of other cities have undertaken similar programs. Portland, Oregon, several years ago worked out a standardization which is substantially the same as that of Chicago and is now partially in effect. In 1914 Houston, Texas, adopted practically a reproduction of the Chicago scheme. During the last two years Oakland, California, has reclassified its service on the basis of duties and is gradually putting into effect a standardization that varies but slightly from its Chicago pattern. On October 30, 1915, St. Paul took a similar step and now has in force a standardization ordinance which in the main is a copy of the same original that the other cities have followed.

THE LOS ANGELES AND PITTSBURGH VARIATIONS

During 1914 Los Angeles county, California, and Pittsburgh, have adopted standardization measures that vary more widely from the Chicago model. Both Los Angeles county and Pittsburgh have made a more searching analysis of the service than is found in any previous classification. Instead of grouping the many different lines of municipal employment into eleven broad classes, as Chicago has done, and then subjecting all the employments in each of these classes to the same grading and scale of compensation, Los Angeles county has made it possible to deal independently with individual lines of work by increasing the number of subdivisions of the service to upwards of fifty. The same departure from former methods is found in the Pittsburgh classification. The Los Angeles standardization, moreover, does not provide for efficiency markings to determine advancement from a lower to a higher salary rate. The first increase comes automatically after one year's service and subsequent increases are made after investigation and favorable recommendation by the bureau of efficiency of the civil service commission. Another noteworthy variation from the Chicago idea is the attempt by Pittsburgh to standardize requirements for admission to each distinct grade of service. Chicago has standard requirements for individual positions, but not for grades.

A number of other cities are engaged at the present time on standardization programs. New York City has well under way the most monumental task of standardization yet attempted in this country. ${ }^{3}$ Philadelphia

${ }^{2}$ See National Municipal Review, vol. iv, p. 662.

${ }^{8}$ Late in February, after this article had gone to press, the New York Bureau of Municipal Research published an extended discussion under the caption "Standardization of Public Employments" in the issue of Municipal Research dated November, 1915. 
and Milwaukee are both engaged in a study of the salary problem, the latter city having rejected a standardization measure in 1913. Similar studies are being carried on by a number of states, among them Ohio, New York and Wisconsin.

A review of various standardization plans, either already in force or now under consideration, reveals a development of ideas common to them all rather than revolutionary departures in fundamentals. All involve a classification of service on the basis of duties; all provide for a simplification and standardization of titles; all assume the application of the merit principle in determining promotion from grade to grade; and all recognize the importance of providing opportunity for advancement in salary even when no change in position or grade has taken place. Development appears principally in the more scientific character of later classifications. In this respect the high water mark thus far probably has been reached by New York City. Its classification and grade specifications not only go into greater detail than any previous effort along this line, but also achieve a degree of administrative flexibility that has been attained by few other standardizations. The New York plan also includes a standardization of requirements similar to that of Pittsburgh.

\section{INCREASES WITHIN GRADES}

There is one aspect of the problem, however, with regard to which we find less unanimity of opinion, and that is the manner of advancing employes to higher salary rates within grades. Three different methods of accomplishing this may be distinguished: First, by making increases automatic at the expiration of fixed periods of time, regardless of the efficiency of the service rendered; second, by making increases dependent upon efficiency, measured by a system of efficiency marking; third, by basing legislative action regarding increases upon special investigation and recommendation by efficiency bureaus.

The first of these methods, that of increasing salaries automatically regardless of efficiency, is open to serious objection. It makes no distinction between employes who have given unusual satisfaction in the performance of duty and employes who have simply managed to hold their jobs. It is preferable, however, to the flat salary rate which permits of no increases whatever. The Los Angeles standardization provides for automatic advancement in case of first increase only, and no other standardization embodies this method even in limited measure.

The second method, which includes the factor of efficiency ascertained by a system of efficiency marking, is theoretically more nearly correct, but practically more difficult to apply. The idea of keeping record of the efficiency of employes is not entirely new, and in most instances where it has been tried it has fallen short of expectations. Too often these records are kept in a perfunctory manner and prove of little value for 
administrative purposes. Even where they are kept conscientiously, it is difficult to reconcile the markings of different officials who rate employes according to widely varying standards. The theory of efficiency records is sufficiently appealing, however, to warrant further experimentation, and practically every city that has adopted standardization measures has shown its disposition to experiment. Chicago has worked out an elaborate system of efficiency marking which has achieved a certain degree of success. Other cities are adapting the Chicago idea to their local needs. In time, no doubt, improvements will be effected that will make the system a more helpful instrument for determining individual efficiency than it is at present.

The third method, that of basing legislative action regarding increases on investigation and recommendation by efficiency bureaus, is an important feature in the standardizations of Los Angeles and of New York City. In the former it is applied to advancement from the second salary rate to the third, and final, rate; while in the latter it often applies to all increases. In the New York City standardization, however, this method is only supplemental to efficiency markings maintained under the rules of the civil service commission, whereas in Los Angeles county it is the sole means of ascertaining the efficiency factor in advancement. How satisfactory this method will prove still remains to be seen. Naturally a great deal will depend on the amount of freedom which efficiency bodies will enjoy in making their investigations and recommendations.

These and other problems involved in salary standardization no doubt will be simplified by the experience of coming years. At this stage it is enough to know that however imperfect certain methods may be, they are nevertheless vastly superior to the unsystematic practices which they are designed to displace.

The entire standardization movement is still so new that sweeping generalizations with regard to past experience are hardly in order. Even Chicago, the first city to adopt a standardization measure, has had less than six years' experience in administering it. Nevertheless it is quite well established that an immense improvement has been effected in the civil service of that city. No official who is familiar with conditions both prior to and since the adoption of the standardization seems willing to return to the old order. Dire predictions that the total annual outlays for salaries would be increased enormously by the new schedules have not come true. In a large measure the question of compensation for personal service has been taken out of the realm of the lobby and placed on a scientific basis. Whatever shortcomings there may be in the present method of fixing salaries in Chicago they do not compare with the unintelligent blundering and absence of system of former years.

In general we may say that the standardization program accomplishes its main purposes in an acceptable manner. While it is not a panacea, 
it does much to correct conditions that have been so largely responsible for the unattractive character of municipal service in the past. It aims primarily to improve the administrative methods of utilizing human energy to the best advantage of both employes and the service. To that end it simplifies the problem of the legislative body by making available to legislators complete and reliable information to guide them in passing on salary changes. The wide discrepancies in rates of pay for similar positions, unavoidable under the old methods and which proved so demoralizing to employes, can no longer appear if the standardization is adhered to in appropriations. At the same time the way is paved for a more flexible adjustment of salaries to individual needs than was formerly the case. The problem of the civil service commission also is simplified. A classification of service based on duties and providing proper grades for advancement makes possible a more equitable system of promotion than could obtain under the old grading scheme with haphazard salary rates as a basis. These improvements in the methods of dealing with the employment situation are bound in time to work salutary changes in the general tone and character of our municipal service. 